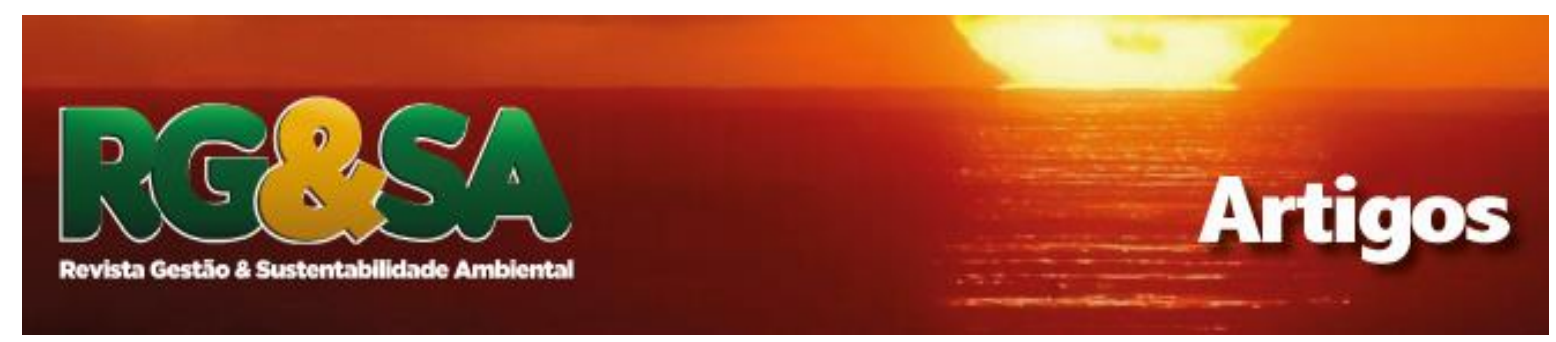

\title{
ABORDAGEM DA SUSTENTABILIDADE NO ENSINO EM DESIGN NO BRASIL: ÊNFASES E LACUNAS
}

DOI: $10.19177 /$ rgsa.v9e0I2020184-203
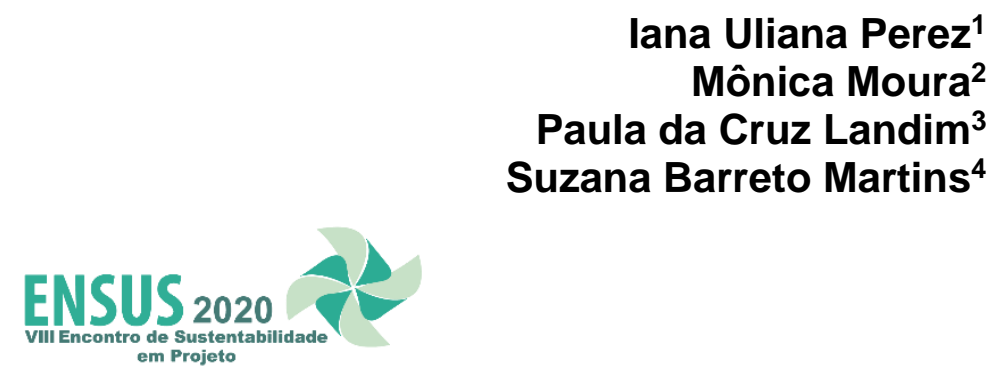

RESUMO

Versão atualizada e expandida de um artigo das autoras publicado nos anais do VIII Encontro de Sustentabilidade em Projeto (ENSUS), este artigo tem como objetivo identificar e analisar publicações contemporâneas sobre o ensino em design no Brasil que tenham como foco a sustentabilidade. Para isso, realizou-se uma revisão bibliográfica sistemática de artigos revisados por pares e de teses e dissertações da área de conhecimento do design. Após a realização de buscas nos principais periódicos brasileiros de design e no Catálogo de Teses e Dissertações da Capes, foram identificadas 23 publicações relativas ao período entre 2008 e maio de 2020 . Os resultados apontam ênfases com relação à dimensão ambiental e ao projeto de produtos mais sustentáveis, assim como indicam a importância de abordar a sustentabilidade na educação como tema transversal por meio de metodologias ativas de ensino-aprendizagem. As lacunas identificadas envolvem as dimensões social e econômica da sustentabilidade, além da inclusão de novas abordagens como o design de serviços e a atuação para a promoção de novos cenários de consumo suficiente. Para isso, é importante que o paradigma ecocêntrico seja adotado no ensino em design, de modo a promover a transformação não apenas da prática projetual, como da própria mentalidade e atuação dos designers.

Palavras-chave: Design Contemporâneo. Educação. Revisão Bibliográfica Sistemática. Temas transversais. Paradigma Ecocêntrico.

\footnotetext{
${ }^{1}$ Doutoranda do Programa de Pós-Graduação em Design da UNESP - Universidade Estadual Paulista. Mestra em Design pela UFPR - Universidade Federal do Paraná. Atualmente é membro e pesquisadora do Laboratório e Grupo de Pesquisa em Design Contemporâneo: sistemas, objetos e cultura (UNESP) e do Grupo de Pesquisa em Design, Sustentabilidade e Inovação (UEL). E-mail: iana.uli@gmail.com
}

${ }^{2}$ Líder do Grupo de Pesquisa Design Contemporâneo: sistemas, objetos e cultura (CNPq/UNESP). Professora do Departamento de Design e Orientadora no Programa de Pós-graduação em Design da UNESP. Realizou pós-doutorado na Pontifícia Universidade Católica (PUC-Rio) e na 
Universidade do Minho. Doutora e Mestra em Comunicação e Semiótica (PUC-SP). E-mail: monicamoura.design@gmail.com

\begin{abstract}
${ }^{3}$ Professora no Departamento de Design e coordenadora do Programa de Pós-graduação em Design da UNESP. Realizou pós-doutorado Universidade de Arte e Design de Helsinque na Finlândia. Livre-docente em Design de Produto (UNESP), Doutora em Arquitetura e Urbanismo (USP), Mestra em Geografia (UNESP) e graduada em Arquitetura e Urbanismo (USP). E-mail: paula.cruz-landim@unesp.br
\end{abstract}

\footnotetext{
${ }^{4}$ Docente no Departamento de Design da UEL e líder Grupo de Pesquisa em Design, Sustentabilidade e Inovação. Doutora em Engenharia de Produção (Universidade Federal de Santa Catarina) e Mestra em Ergonomia (Universidade Nacional Autônoma do México-UNAM), realizou pós-doutorado na UFPR. E-mail: suzanabarreto@onda.com.br
}

\title{
THE SUSTAINABILITY APPROACH IN DESIGN EDUCATION IN BRAZIL: EMPHASIS AND GAPS
}

\begin{abstract}
An updated and expanded version of an article by the authors published in the proceedings of the VIII Encontro de Sustentabilidade em Projeto (ENSUS), this article aims to identify and analyze contemporary publications on design teaching in Brazil that focus on sustainability. For this, we carried out a systematic bibliographic review of articles reviewed by peers and of theses and dissertations in the area of design knowledge. After searching the leading Brazilian design journals and the Capes Thesis and Dissertations Catalog, we identified 23 publications for the period between 2008 and May 2020. The results point out emphases regarding the environmental dimension and the design of more sustainable products, as well as indicating the importance of addressing sustainability in education as a transversal theme through active teaching-learning methodologies. The identified gaps involve the social and economic dimensions of sustainability, in addition to the inclusion of new approaches such as service design and action to promote new scenarios of sufficient consumption. For this, it is crucial to adopt the ecocentric paradigm in design teaching, to promote the transformation not only of the design practice but also of the designers' mentality and performance.
\end{abstract}

Keywords: Contemporary Design. Education. Systematic Literature Review. Cross-cutting themes. Ecocentric Paradigm.

\section{INTRODUÇÃO}

A discussão sobre a necessidade de uma atuação mais responsável com relação à sociedade e ao meio ambiente por parte dos designers não é nova, mas tem se tornado cada vez mais premente no cenário contemporâneo, vide a intensificação dos impactos ambientais e a perpetuação de problemáticas sociais como a desigualdade. Sendo assim, urge formar designers aptos a atuar com 
responsabilidade e, além disso, prepará-los para contribuir na promoção de mudanças na sociedade e para adaptar-se a novas perspectivas de atuação profissional, como no caso dos novos cenários de consumo suficiente propostos por Santos (2009) e Sampaio et al. (2018).

Antes de traçar planos para o futuro do ensino em design, contudo, é importante conhecer o panorama contemporâneo a respeito de como a sustentabilidade tem sido abordada durante a formação dos novos designers. Considerando a dificuldade de implementação de mudanças no ensino superior de design, há que se questionar como as questões complexas relacionadas à sustentabilidade têm sido abordadas nas universidades brasileiras.

Com o intuito de traçar esse panorama, a pesquisa aqui relatada teve como objetivo identificar e analisar publicações contemporâneas sobre o ensino em design no Brasil que tenham como foco a sustentabilidade. Para isso, realizou-se uma revisão sistemática de artigos revisados por pares e de teses e dissertações da área de conhecimento do design. A questão de pesquisa colocada é: quais são as ênfases e lacunas teóricas com relação à abordagem da sustentabilidade no ensino em design?

\section{MÉTODO}

A pesquisa aqui relatada, de finalidade básica, adotou abordagem quantiqualitativa de natureza exploratória, sendo o seu delineamento a Revisão Bibliográfica Sistemática (RBS). Trata-se de um procedimento metódico, transparente e replicável, que segue um método explícito e planejado. A RBS é utilizada para "mapear trabalhos publicados no tema de pesquisa específico", resultando em uma síntese do conhecimento existente que permita identificar ênfases e lacunas (CONFORTO; AMARAL; SILVA, 2011, p. 3; DRESCH; LACERDA; ANTUNES JÚNIOR, 2015).

Para a condução da RBS, foi adotado o roteiro de Conforto, Amaral e Silva (2011), que recomendam seguir 15 etapas divididas em três fases principais: Entrada, Processamento e Saída. O Quadro 1 resume as principais decisões referentes aos procedimentos metodológicos da fase de Entrada. Foram selecionadas como fontes primárias teses e dissertações, além de artigos revisados por pares. Os trabalhos 
de pós-graduação foram pesquisados por meio do Catálogo de Teses e Dissertações da Capes, enquanto os artigos foram coletados utilizando-se os recursos de busca dos sites de diferentes periódicos de design, tendo sido selecionadas revistas com maior qualificação de acordo com a Capes, além de um periódico cuja temática principal é o design para a sustentabilidade.

\section{Quadro 1 - Procedimentos metodológicos da RBS}

\begin{tabular}{|c|c|c|}
\hline $\begin{array}{l}\text { Fontes } \\
\text { primárias }\end{array}$ & $\begin{array}{l}\text { Catálogo de Teses e } \\
\text { Dissertações da Capes. }\end{array}$ & $\begin{array}{l}\text { Estudos em Design, Design \& } \\
\text { Tecnologia, Projética, } \\
\text { Educação Gráfica, Revista D, Mix } \\
\text { InfoDesign, } \\
\text { Strategic Design Research }\end{array}$ \\
\hline $\begin{array}{l}\text { Strings de } \\
\text { busca }\end{array}$ & $\begin{array}{l}\text { sustenta* AND ensino } \\
\text { sustenta* AND (educação NOT } \\
\text { ensino) }\end{array}$ & $\begin{array}{l}\text { educação } \\
\text { OR ensino }\end{array}$ \\
\hline $\begin{array}{l}\text { Data das } \\
\text { buscas }\end{array}$ & \multicolumn{2}{|c|}{ dezembro de 2019, com atualização em 15 de maio de 2020} \\
\hline $\begin{array}{l}\text { Critérios de } \\
\text { inclusão }\end{array}$ & \multicolumn{2}{|c|}{$\begin{array}{l}\text { 1. período de publicação: entre } 2008 \text { e maio de 2020; } \\
\text { 2. tipo de publicação: teses e dissertações ou artigos revisados por pares da } \\
\text { área de design; } \\
\text { 3. temática principal: ensino em design (em qualquer nível, seja fundamental, } \\
\text { técnico ou superior) relacionado à sustentabilidade. }\end{array}$} \\
\hline $\begin{array}{l}\text { Critérios de } \\
\text { exclusão }\end{array}$ & $\begin{array}{l}\text { 1. trabalhado desenvolvido em PPG } \\
\text { de outras de áreas de conhecimento } \\
\text { que não sejam "desenho industrial"; } \\
\text { 2. dissertação de mestrado } \\
\text { profissional; } \\
\text { 3. não obter acesso ao arquivo com a } \\
\text { dissertação ou tese completa. }\end{array}$ & $\begin{array}{l}\text { Abordar sustentabilidade de maneira } \\
\text { superficial, como temática acessória. }\end{array}$ \\
\hline \multirow{2}{*}{$\begin{array}{l}\text { Filtros } \\
\text { adotados }\end{array}$} & \multicolumn{2}{|c|}{ Filtro 1: análise dos dados de publicação, título e resumo. } \\
\hline & \multicolumn{2}{|c|}{$\begin{array}{l}\text { Filtro 2: leitura da introdução, método, resultados/discussão e } \\
\text { conclusões/considerações finais. }\end{array}$} \\
\hline $\begin{array}{l}\text { Critério de } \\
\text { qualificação }\end{array}$ & \multicolumn{2}{|c|}{ Explicitação do método empregado e qualidade da execução. } \\
\hline
\end{tabular}

Fonte: As Autoras (2020)

A segunda fase, Processamento, envolveu a realização das buscas, análise dos resultados e documentação. Todos os dados das buscas foram registrados em planilhas. Os trabalhos selecionados no Filtro 1 foram salvos em um

R. gest. sust. ambient., Florianópolis, v. 9, n. esp, p. 184-203, jul. 2020. 
software de gestão de referências, como sugerido por Conforto, Amaral e Silva (2011). Por fim, a terceira fase, Saída, abarca o cadastro e arquivo das publicações, elaboração do relatório com síntese dos resultados e construção de modelos teóricos. Para a análise e sintetização do conteúdo dos trabalhos, foram criadas tabelas comparativas nas quais foram registradas as principais informações de cada publicação relativas a: temática principal; objetivos da pesquisa; dimensões da sustentabilidade enfatizadas; níveis de maturidade do design para a sustentabilidade em que se enquadra o trabalho; recorte geográfico da pesquisa; recorte de ensino (nível de ensino e áreas do design); método/procedimentos metodológicos; principais resultados e contribuições da pesquisa. A seguir, é apresentada a síntese dos resultados obtidos.

\section{RESULTADOS}

Após a realização das buscas e conferência das publicações, foram selecionados para análise 12 dissertações e 11 artigos, totalizando 23 publicações. Nenhuma tese foi identificada, o que pode indicar que essa temática de pesquisa ainda não está suficientemente amadurecida. Dos artigos selecionados, dois relatam a pesquisa de dissertações também selecionadas, a saber, Neves (2008) e Silva (2015). Quanto aos periódicos consultados, percebe-se predominância de resultados na Mix Sustentável ( $n=8$ ou $73 \%$ dos artigos selecionados). Outros periódicos onde foram obtidos resultados $(n=1)$ são Projética, Educação Gráfica e Estudos em Design.

Com relação à origem das pesquisas realizadas (Figura 1), a maioria foi conduzida por pesquisadores de universidades da região Sul ( $n=17$ ou $74,3 \%$ ). Os demais trabalhos foram executados por pesquisadores de universidades do Sudeste, mais especificamente dos estados de São Paulo $(n=3)$ e Minas Gerais $(n=2)$, e do Nordeste $(n=1)$, em Campina Grande (PB). Dentre as universidades, destacam-se a Universidade Federal do Paraná (UFPR), a Universidade Federal de Santa Catarina (UFSC) e o Centro Universitário Ritter dos Reis (UniRitter), todos com quatro trabalhos (embora um dos artigos da UniRitter seja relativo a uma dissertação também selecionada). Outra universidade que se destacou, com três publicações, foi a Universidade Federal do Rio Grande do Sul (UFRGS). A 
Universidade Estadual Paulista (Unesp) também apresenta três publicações, mas duas delas (um artigo e uma dissertação) tratam da mesma pesquisa.

Figura 1- Polos de pesquisa identificados na RBS
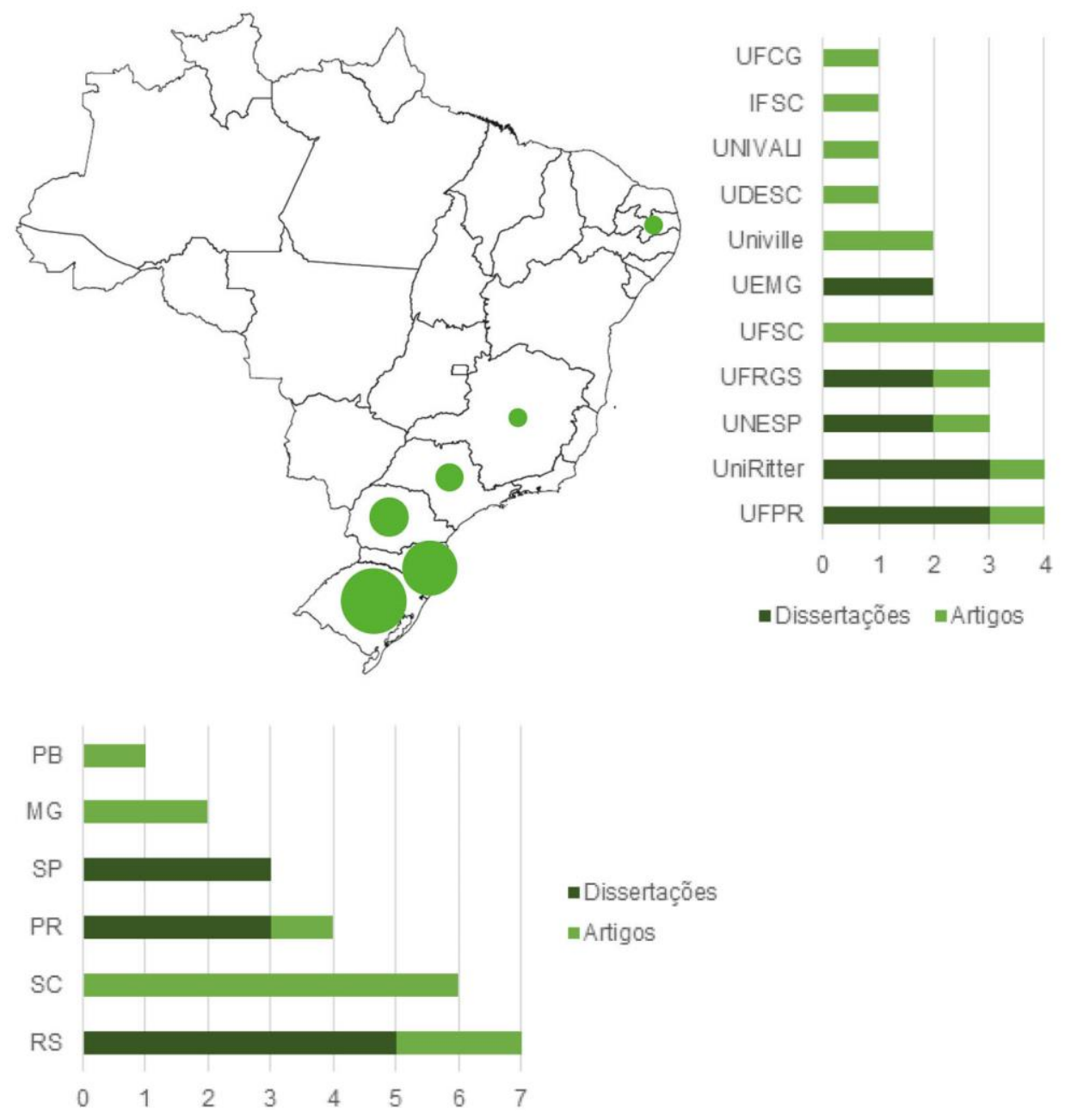

Fonte: As Autoras (2020)

A Figura 2 apresenta uma linha do tempo, na qual foi registrado o ano de publicação dos trabalhos selecionados. A primeira pesquisa é a de Neves (2008), com sua dissertação sobre aprendizado baseado em problemas (PBL). Após, houve pouca variação no número de publicações por ano, até ocorrer um pico de trabalhos em 2014. Desde então, contudo, apresenta-se uma queda, a qual é mais considerável dentre as dissertações, enquanto a taxa de publicação dos artigos tem variado entre um e dois por ano. Apesar dessa queda, a maioria dos trabalhos selecionados ( $n=14$ ou 61\%) foi publicada nos últimos cinco anos, isto é, a partir de 2014. 
Figura 2- Número de publicações por ano

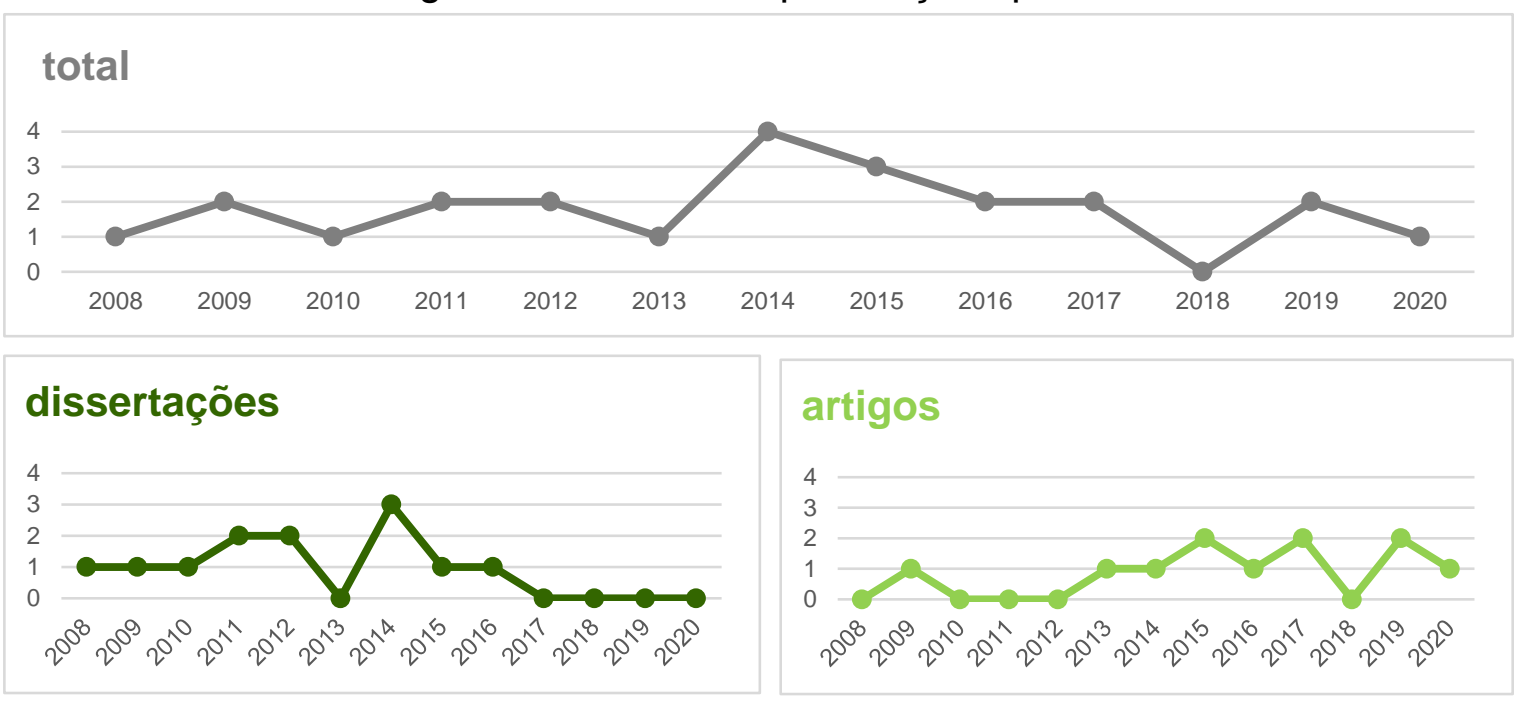

Fonte: As Autoras (2020)

Quanto ao nível de ensino enfocado nas pesquisas analisadas, destaca-se o ensino superior (seja bacharelado ou tecnólogo), com 10 dissertações e 10 artigos. Dois desses artigos discutem o nível de pós-graduação (SANTOS; COSTA, 2014; EVERLING; SOBRAL; CAVALCANTI, 2020), enquanto uma dissertação aborda, além do ensino superior, também o ensino técnico (MOUCHREK, 2014). Duas dissertações e um artigo discorrem sobre o uso do design na educação básica para abordar temáticas relacionadas à sustentabilidade (GOMES, 2009; MAGALHÃES, 2011; MUNIZ; PAZMINO, 2019). No que diz respeito às áreas de design sobre as quais tratam os trabalhos, a maioria $(n=12)$ aborda o design em geral, sem especificar o ensino de uma habilitação em especial. Por sua vez, seis trabalhos lidam com design de produto, dois com design gráfico (MOL, 2014; SMYTHE JUNIOR, 2010), um com design de moda (PINHEIRO, 2012) e um com design de serviços (SANTOS; COSTA, 2014).

Sobre métodos utilizados, todos realizaram pesquisas qualitativas, sendo que apenas dois trabalhos envolveram pesquisa quanti-qualitativa (VENÂNCIO, 2012; ENSSLIN et al., 2013). Embora todos os pesquisadores tenham realizado revisão bibliográfica, apenas três publicações (uma dissertação e dois artigos) utilizaram exclusivamente esse método (NEVES, 2008; NEVES; ALENCAR, 2009; EVERLING; SOBRAL; CAVALCANTI, 2020). Também houve predomínio de pesquisa documental $(n=10)$, uma vez que muitas investigações envolviam a 
análise de grades curriculares e ementas, ou mesmo de trabalhos desenvolvidos por alunos. Outras técnicas de coleta de dados utilizadas foram questionários $(n=6)$, entrevistas $(n=4)$ e grupos focais $(n=4)$.

Três publicações fizeram um levantamento sobre os cursos de design existentes no Brasil, sendo que duas delas analisaram grades curriculares e ementas de disciplinas (VENÂNCIO, 2012 - sobre ensino de valorização territorial; CALEGARI; OLIVEIRA, 2017 - pesquisa restrita a instituições federais de ensino). Uma dissertação fez o mesmo, mas com enfoque em cursos de design gráfico (SMYTHE JUNIOR, 2010). Também houve pesquisas semelhantes com recortes geográficos mais específicos, analisando-se os cursos de design da região metropolitana de Porto Alegre (SELAU, 2014) e do estado de Santa Catarina (PAZMINO; SANTOS, 2017). Algumas dessas pesquisas também coletaram dados sobre os cursos diretamente com seus coordenadores e professores.

Muitos trabalhos $(n=9)$ envolveram pesquisa de campo, com desenvolvimento ou teste, em sala de aula, de soluções de ensino (MOL, 2010; SMYTHE JUNIOR, 2010; MAGALHÃES, 2011; MORAES, 2011; MOUCHREK, 2014; SILVA, 2015; SILVA; RIBEIRO, 2015; PAZMINO, 2015; SILVA; CLEMENTINO; NEGROMONTE, 2019). Outros trabalhos $(n=5)$ realizaram análises baseadas em atividades anteriormente desenvolvidas em determinadas instituições de ensino, como disciplinas (SANTOS; COSTA; 2014; PINHEIRO, 2012), estágios (PINHEIRO, 2012), trabalhos de conclusão de curso (NEVES et al., 2016; PINHEIRO, 2012), projetos de extensão (ZAMBENEDETTI, 2016) e projetos sobre sustentabilidade (GOMES, 2009).

Os principais temas das publicações analisadas são apresentados na Figura 3. Ressalta-se que alguns trabalhos encaixam-se em mais do que uma temática, motivo pelo qual a soma dos itens no gráfico é superior a 23, total de dissertações e artigos analisados. Percebe-se que há diversidade de temas, dentre os quais destaca-se a abordagem da sustentabilidade como tema transversal (e.g., SELAU, 2014; PAZMINO; SANTOS, 2017), o que pode ocorrer por meio do desenvolvimento de projetos integradores (ENSSLIN et al., 2013). Outras temáticas de destaque são a educação através do design como uma alternativa para a promoção da sustentabilidade (e.g., GOMES, 2009; MAGALHÃES, 2011) e os objetos de aprendizagem (e.g., SILVA, 2015; SILVA; RIBEIRO, 2015; PAZMINO, 2015). 
Também ressaltam-se os trabalhos que apresentam soluções para 0 ensino de projeto relacionado ao design para a sustentabilidade. Dentre essas soluções, tem-se: um jogo para prever requisitos de sustentabilidade no desenvolvimento de projetos (SILVA, 2015; SILVA; RIBEIRO, 2015); método para a inclusão do conceito de Life Cycle Design no primeiro período do Curso de Design (SILVA; CLEMENTINO; NEGROMONTE, 2019); diretrizes de sustentabilidade para orientar a inserção da sustentabilidade em cursos de design gráfico (SMYTHE JUNIOR, 2010); sistematização de procedimentos orientados à sustentabilidade e sua integração às metodologias projetuais para aplicação no ensino de Metodologia de Projeto (MORAES, 2011); método de ensino para projetos de design de superfície relacionados à transposição de elementos e valores culturais presentes na identidade de um território (MOL, 2014).

Figura 3 - Principais temáticas abordadas nos trabalhos analisados

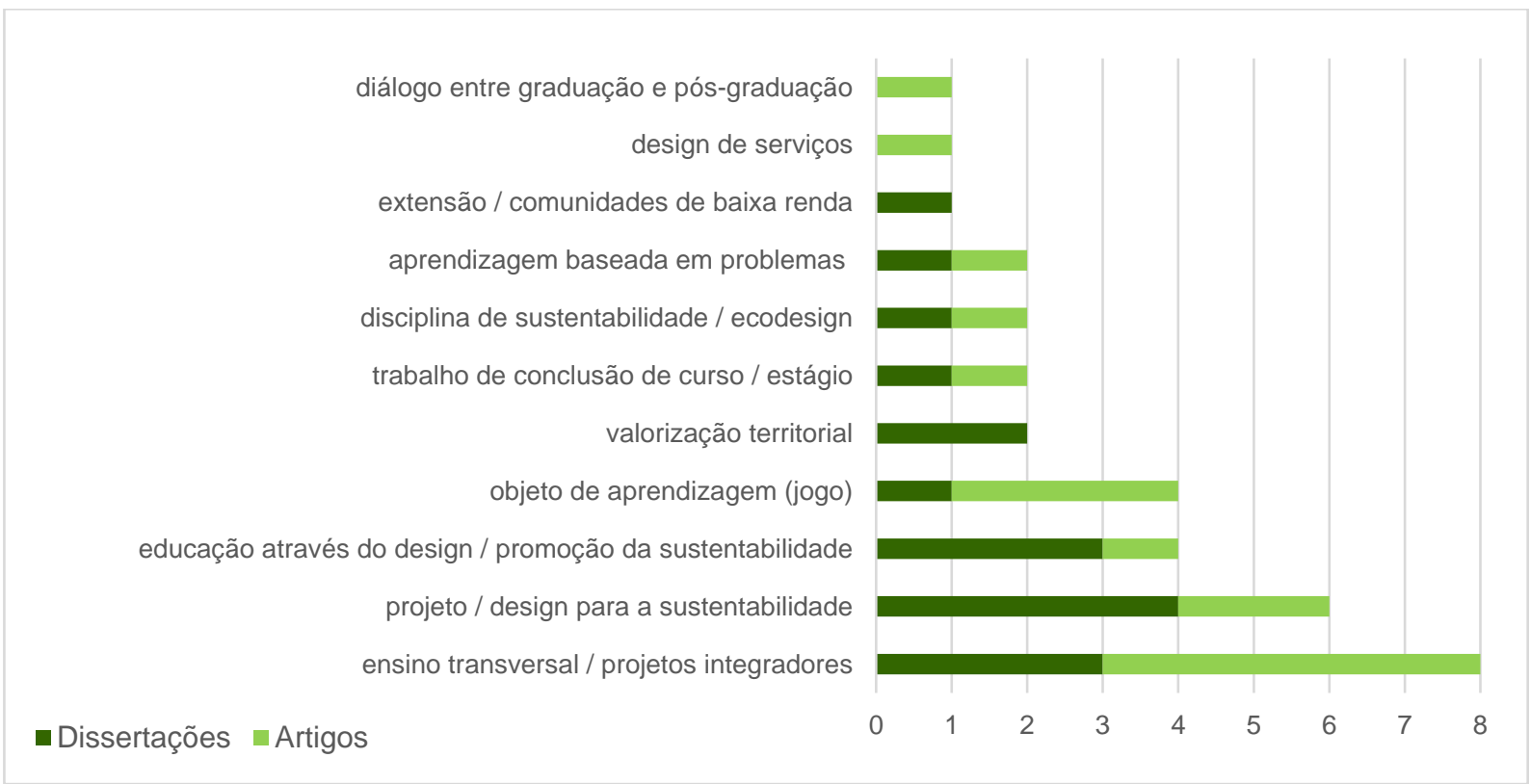

Fonte: As Autoras (2020)

Para analisar a abordagem da sustentabilidade adotada nos trabalhos selecionados, foram utilizados dois constructos teóricos que permitem sua categorização: as dimensões da sustentabilidade e os níveis de maturidade do design para a sustentabilidade. Embora haja uma diversidade de dimensões da sustentabilidade, aqui foi adotada a divisão mais comum de três dimensões, 
conforme indicado por Vezzoli et al. (2018): ambiental, social e econômica. Segundo os autores supracitados, essa subdivisão da sustentabilidade contribui para o direcionamento de estratégias para a sua efetivação. Já a categoria de níveis de maturidade do design para a sustentabilidade foi inicialmente postulada por Manzini e Vezzoli (2002), sendo posteriormente revisada por Santos (2009), Vezzoli (2010) e Sampaio et al. (2018). Tendo como base os autores anteriormente referenciados, neste artigo adotam-se para a análise cinco níveis, que tratam, progressivamente, de abordagens relativas a: 1) fluxos de processos, com ênfase na seleção e uso de materiais e energia; 2) seleção de materiais; 3) projeto do ciclo de vida do produto; 4) projeto de sistemas de produtos-serviços sustentáveis (S.PSS); 5) atividades no plano cultural que promovam novos estilos de vida mais sustentáveis, assim como o consumo suficiente, a equidade e a coesão social.

$\mathrm{Na}$ Figura 4, são ilustrados os resultados relativos a essas categorias de abordagem da sustentabilidade. Nota-se que há predomínio (52\%) de publicações que enfocam apenas a dimensão ambiental, enquanto outras $(n=6)$ consideram simultaneamente as três dimensões (e.g. SILVA, 2015; SILVA; RIBEIRO, 2015; SELAU, 2014). Poucos trabalhos abordam especificamente a dimensão social, sendo que dois deles (VENÂNCIO, 2012; MOL, 2014) tratam da temática de valorização territorial, que pode ser relacionada ao princípio heurístico da dimensão social "fortalecer e valorizar os recursos locais", conforme a definição presente em Vezzoli et al. (2018). A terceira publicação (ZAMBENEDETTI, 2016) tem como temática 0 trabalho de projetos de extensão universitária com comunidades de baixa renda. Uma dissertação (MORAES, 2011), por sua vez, enfoca predominantemente a dimensão ambiental, mas com inclusão incremental de preocupações sociais. Nenhum dos trabalhos selecionados tem como foco a dimensão econômica. 
Figura 4 - Enfoques relativos à abordagem da sustentabilidade

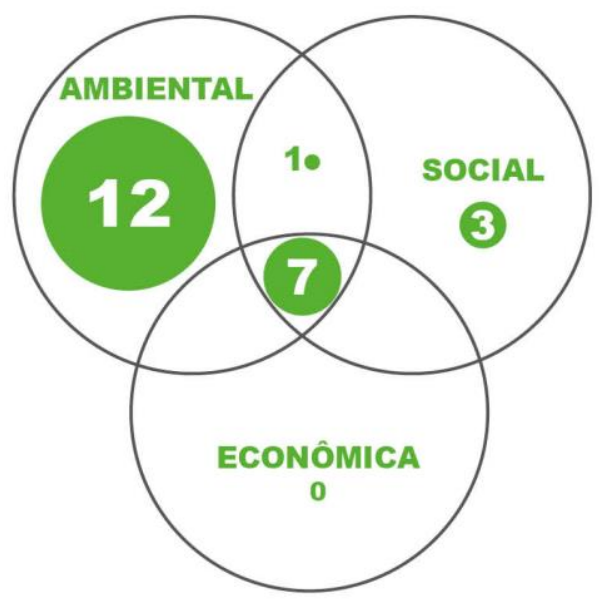

DIMENSÕES DA SUSTENTABILIDADE

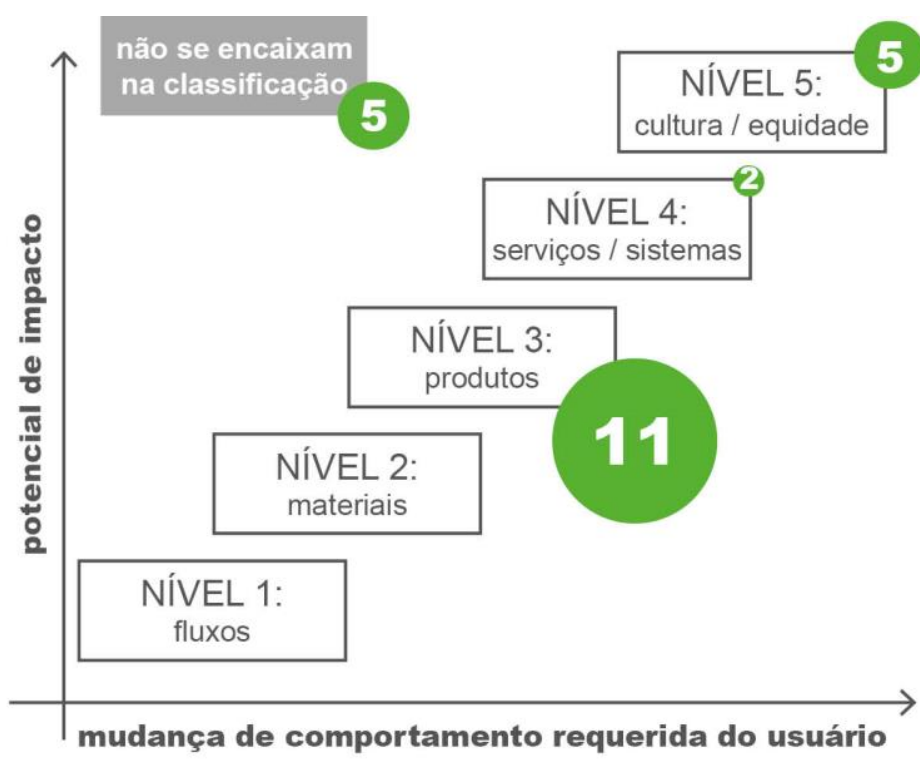

NÍVEIS DE MATURIDADE

Fonte: As Autoras (2020)

Com relação aos níveis de maturidade, destaca-se que três dissertações (GOMES, 2009; MORAES, 2011; SILVA, 2015) e um artigo (SILVA; CLEMENTINO; NEGROMONTE, 2019) fizeram referência direta aos níveis de maturidade, seja por meio de Santos (2009), Manzini e Vezzoli (2002), Vezzoli (2010) ou Sampaio et al. (2018), respectivamente. Muitos trabalhos (48\%) apresentam abordagem relativamente avançada nesse sentido, pois encontram-se no terceiro nível, que, segundo Sampaio et al. (2018), trata do projeto de novo produto intrinsecamente mais sustentável. Esses trabalhos abarcam também preocupações relativas aos dois primeiros níveis. No quarto nível, foram identificados apenas dois trabalhos, um que relatou o projeto de um S.PSS por parte de alunos participantes da pesquisa (MORAES, 2011) e outro que trata do design de serviços (SANTOS; COSTA; 2014). Relativas ao quinto nível, foram identificadas cinco publicações, quatro que tratam da educação através do design (GOMES, 2009; MAGALHÃES, 2011; MOUCHREK, 2014; MUNIZ; PAZMINO, 2019) e uma que aborda o assim denominado "design social" no contexto da extensão universitária (ZAMBENEDETTI, 2016). Nenhuma dessas publicações, contudo, se aprofunda em questões relativas à mudança de estilo de vida, consumo suficiente ou equidade

R. gest. sust. ambient., Florianópolis, v. 9, n. esp, p. 184-203, jul. 2020. 
e coesão social, embora apresentem abordagens de ensino com potencial para promover transformações sociais. Por fim, esclarece-se que cinco publicações (EVERLING; SOBRAL; CAVALCANTI, 2020; MOL, 2014; VENÂNCIO, 2012; NEVES, 2008; NEVES; ALENCAR, 2009) lidavam com temáticas e abordagens que não se encaixavam nessa classificação por níveis.

\section{DISCUSSÃO}

O resultado de 23 publicações (dentre dissertações e artigos) indica haver preocupação com relação a como o ensino em design tem tratado (ou não) a sustentabilidade. Primeiramente, destaca-se que grande parte dos trabalhos analisados $(n=9 ; 39 \%)$ adota a perspectiva do desenvolvimento sustentável. Ainda que muitos autores, assim como instituições e autoridades, considerem o desenvolvimento sustentável como o modelo ideal para se equilibrar as necessidades da sociedade com os limites do meio ambiente, existem críticas quanto à sua abordagem antropocêntrica, conforme apontado por Sampaio et al. (2018). Nesse sentido, a dissertação de Magalhães (2011) se destaca por adotar a perspectiva da ecologia profunda, a qual apresenta uma visão sistêmica e ecocêntrica, enfatizando o valor intrínseco da natureza, independentemente dos benefícios que possa ter para os seres humanos (SAMPAIO et al. 2018; CAPRA, LUISI, 2014). De maneira semelhante, Pazmino e Santos (2017) também discutem o paradigma antropocêntrico e apresentam o que chamam de "Novo Paradigma Ecológico", sugerindo que essa seja a melhor forma de abordar a sustentabilidade no ensino em design.

Ainda sobre as diferentes visões que podem ser adotadas ao se abordar a sustentabilidade, ressalta-se que alguns trabalhos indicam a necessidade de mudança de paradigma (PAZMINO; SANTOS, 2017; NEVES, 2008) e de valores (NEVES et al., 2016; MAGALHÃES, 2011; NEVES, 2008) para a construção de uma sociedade sustentável. Como apontam Capra e Luisi (2014, p. 39), "a questão dos valores tem importância fundamental para a ecologia profunda." Isso porque mudar o atual paradigma de exploração do meio ambiente e de crescimento econômico baseado no consumo de bens físicos requer, primeiramente, uma mudança de valores, 
os quais devem ser trabalhados no ensino em design para que os futuros profissionais possam atuar na construção de uma nova sociedade sustentável.

Relacionadas a essas mudanças na sociedade, estão as de estilo de vida e de comportamento, abordadas por seis trabalhos (NEVES, 2008; GOMES, 2009; MAGALHÃES, 2011; ENSSLIN et al., 2013; MOUCHREK, 2014; NEVES et al., 2016). O design pode promover essas mudanças de estilo de vida e de comportamento, atuando assim no quinto nível de maturidade. Contudo, apenas os trabalhos que trataram da educação através do design (GOMES, 2009; MAGALHÃES, 2011; MOUCHREK, 2014) aprofundaram-se nessa atuação profissional, ainda que não tenham enfatizado como preparar os designers para exercerem esse papel de educadores e promotores de mudança. Ainda com relação ao quinto nível, embora alguns pesquisadores tenham mencionado a necessidade de reduzir o consumo (e.g. GOMES, 2008; ENSSLIN et al., 2013), nenhum abordou especificamente o conceito de consumo suficiente. Em oposição, Caligari e Oliveira (2017) não consideram a redução do consumo como uma solução viável.

Desse modo, percebe-se haver uma lacuna no que diz respeito à adaptação do ensino em design para a promoção uma sociedade mais sustentável baseada no paradigma ecocêntrico (pautado em um sistema de valores centrados na natureza) e em um modelo econômico de suficiência, sobretudo se considerarmos que a atuação do designer nesse contexto seria completamente diferente da atual, que tem como foco o desenvolvimento e a promoção de artefatos físicos. Nesse sentido, dois trabalhos abordam algumas mudanças relacionadas a preparar os designers para atuar no desenvolvimento de serviços (MORAES, 2011; SANTOS; COSTA, 2014), enquadrando-se no quarto nível de maturidade. No entanto, há uma ausência de competências no Brasil com relação ao design de serviços e de S.PSS, como apontam Vezzoli et al. (2018). Segundo esses autores, ainda não há a habilitação em design de serviços e o seu ensino na graduação tem estado restrito a algumas poucas universidades que ofertam disciplinas optativas (e.g. SANTOS; COSTA, 2014), cursos de extensão ou oficinas.

Cabe destacar também que nenhuma pesquisa analisada abordou como preparar designers para atuarem na promoção de equidade e coesão social. Zambenedetti (2016) tangenciou essa questão ao discutir como a extensão universitária promove a atuação com comunidades de baixa renda, apontando a 
necessidade de adotar as abordagens do design social, do design centrado no ser humano e das práticas participativas de projeto, além de ter enfatizado o quanto 0 trabalho na extensão pode preparar os estudantes de design para atuar com design social. Contudo, a pesquisadora não se aprofundou nas questões relacionadas especificamente à promoção de equidade e coesão social, dando mais destaque à abordagem de sustentabilidade referente ao uso de materiais reutilizados no desenvolvimento das atividades do projeto de extensão analisado.

Ainda sobre essa questão, ressalta-se haver uma lacuna quanto à dimensão social, visto que os outros dois trabalhos que trataram dela abordaram uma temática mais específica, a valorização territorial, havendo necessidade de incluir no ensino em design outras questões relativas à dimensão social do design para a sustentabilidade, como os apontados por Vezzoli et al. (2018): melhorar as condições de emprego e trabalho; melhorar a equidade e a justiça na relação entre stakeholders; favorecer e integrar os frágeis e marginalizados; melhorar a coesão social. A lacuna relativa à dimensão social é reforçada também pelos trabalhos que avaliaram as grades curriculares dos cursos de design, análise esta que revela a ênfase que as disciplinas sobre sustentabilidade dão à dimensão ambiental e a questões relativas apenas aos três primeiros níveis de maturidade do design para a sustentabilidade (SMYTHE JUNIOR, 2010; CALEGARI; OLIVEIRA, 2017; PAZMINO; SANTOS, 2017).

No que diz respeito às práticas educativas, muitos dos trabalhos analisados apontam a necessidade de mudar o atual paradigma de ensino. Sete publicações questionam a divisão e especialização do conhecimento, propondo a abordagem da sustentabilidade não como uma disciplina isolada, mas como um tema transversal de abordagem interdisciplinar que perpassa todas as atividades desenvolvidas durante o curso. Algumas propostas nesse sentido vão desde a mera reformulação das ementas das disciplinas já existentes (SELAU, 2014), à promoção de projetos integradores (ENSSLIN et al., 2013) e até a mais disruptiva abordagem do aprendizado baseado em problemas (PBL), o qual promove a integração dos conteúdos (NEVES, 2008; NEVES; ALENCAR, 2009). Por outro lado, alguns trabalhos enfatizam a importância de disciplinas isoladas para o ensino de questões relativas à sustentabilidade, como Pinheiro (2012). Muitos trabalhos também apontaram a importância de adotar metodologias ativas de ensino- 
aprendizagem, como a abordagem do PBL proposta por Neves (2008) e Neves e Alencar (2009), assim como os projetos integradores discutidos por Ensslin et al. (2013), ou ainda o uso de jogos de aprendizagem, objeto de estudo de Pazmino (2015), Silva (2015), Silva e Ribeiro (2015).

Ainda que a abordagem transversal tenha sido defendida em muitas publicações, parte das pesquisas realizadas avaliou se cursos de design abordavam ou não a sustentabilidade ao procurar, em suas grades curriculares, por disciplinas específicas sobre o tema (e.g., CALEGARI; OLIVEIRA, 2017; PAZMINO; SANTOS, 2017; SELAU, 2014; SMYTHE JUNIOR, 2010). Dos resultados apresentados nesses estudos, observa-se que poucos cursos oferecem esse tipo de disciplina e, quando o fazem, apresentam abordagens muito distantes, com nomenclaturas e conteúdos bastante diversos, e em muitos casos as disciplinas sobre sustentabilidade são ofertadas em fases já avançadas, no terceiro ou quarto ano. As pesquisas anteriormente citadas revelam que a maioria dos cursos de design ainda não incluiu a sustentabilidade no ensino em design como algo intrínseco ao projeto, abordando-a como item acessório apenas nas etapas finais do processo de design ou mesmo nos últimos anos do curso de graduação. Esse fato reafirma a visão da cultura de "didatismo reativo" do ensino em design brasileiro, defensivo com relação a toda mudança, apontada por Cardoso (2013), para quem existe a necessidade de uma abordagem mais aprofundada das questões ambientais e sociais, visto sua complexidade.

Para que a sustentabilidade seja, efetivamente, abordada como tema transversal no ensino em design, e para que este ensino prepare os designers para os novos desafios exigidos pelas emergentes crises ambiental e climática, é necessário superar essa cultura de "didatismo reativo". Pois não só o ensino em design deve mudar, como também a atuação e a mentalidade dos designers. É preciso que o paradigma ecocêntrico seja incorporado ao design e que este se alinhe a uma perspectiva de consumo suficiente, a qual tornará premente a reformulação do papel do design para além do projeto de produtos e de serviços. Essa transformação essencial, e até mesmo drástica, da profissão deve ser fomentada pelo ensino em design, sem o qual os designers ou não conhecerão suas possibilidades para além do mercado convencional de design, ou não estarão devidamente preparados para enfrentar os desafios postos por uma nova prática profissional. 


\section{CONSIDERAÇÕES FINAIS}

Por meio da busca no Catálogo de Teses e Dissertações da Capes e em alguns dos principais periódicos científicos da área de design, foram identificados 23 trabalhos que trataram da abordagem da sustentabilidade no ensino em design nos últimos dez anos. Embora o número seja considerado satisfatório, observa-se que não há nenhuma tese sobre essa temática e o número de dissertações caiu nos últimos anos. Essa queda pode ser parcialmente preenchida pela publicação de artigos mais recentes, mas há quantidade relativamente pequena de publicações por ano sobre o ensino em design atrelado à sustentabilidade.

A análise dessas dissertações e artigos possibilitou identificar algumas ênfases e lacunas de pesquisa. Primeiramente, nota-se predomínio de uma abordagem antropocêntrica atrelada ao paradigma de desenvolvimento sustentável. Poucos trabalhos, por exemplo, citaram a necessidade de desenvolver uma visão ecocêntrica, assim como de promover novos valores ou uma mudança de paradigma. Nesse sentido, os estudos analisados não abordaram de maneira significativa a necessidade de repensar drasticamente o papel do design e o seu ensino para lidar com os problemas ambientais e sociais apresentados nos cenários contemporâneo e futuro.

Por outro lado, as ênfases de pesquisa identificadas sugerem a existência, no campo do ensino em design, de avanços na dimensão ambiental e no terceiro nível de maturidade do design para a sustentabilidade, que trata do desenvolvimento de produtos intrinsecamente mais sustentáveis. Também há alguns progressos com relação às abordagens de ensino, com muitas recomendações para que a sustentabilidade seja tratada como tema transversal e que sejam adotadas metodologias ativas de ensino-aprendizagem, como os jogos de aprendizagem, os projetos integradores ou o aprendizado baseado em problemas.

As lacunas identificadas, portanto, relacionam-se muito mais aos temas tratados que às abordagens de ensino em si. Ressalta-se a necessidade de mais 
pesquisas sobre o ensino referente às dimensões social e econômica da sustentabilidade, além da inclusão de novas possibilidades para a atuação profissional, como o design de serviços e a educação por meio do design. Sendo assim, há uma lacuna relacionada ao quarto e quinto níveis de maturidade do design para a sustentabilidade, relacionados, respectivamente, aos sistemas produto-serviço e à promoção de novos cenários de consumo suficiente, equidade e coesão social.

O panorama aqui apresentado foi traçado a partir os relatos de outras pesquisas, podendo não refletir fielmente a realidade do ensino em design no Brasil. Ademais, a maioria das buscas realizadas limitou-se aos trabalhos que citavam a sustentabilidade, podendo haver outras pesquisas que supram as lacunas aqui identificadas. São necessárias, portanto, novas pesquisas que busquem por palavras-chave mais específicas, por exemplo, tanto às dimensões social e econômica, quanto ao quarto e quinto nível de maturidade. Também é possível que haja outras pesquisas nessa área divulgadas em anais de eventos, os quais não foram considerados neste artigo.

Contudo, a despeito de suas limitações, espera-se que o panorama aqui apresentado contribua para informar a formulação de novas pesquisas que tenham como intuito não só compreender o atual cenário do ensino em design no Brasil no que diz respeito à sustentabilidade, como propor soluções para o avanço da sua abordagem. Os resultados deste artigo também podem oferecer subsídios para a reformulação de ementas e de estratégias de ensino.

\section{AGRADECIMENTOS}

O presente trabalho foi realizado com apoio da Coordenação de Aperfeiçoamento de Pessoal de Nível Superior - Brasil (CAPES) - Código de Financiamento 001.

\section{REFERÊNCIAS}

CALEGARI, E. P.; OLIVEIRA, B. F. de. A sustentabilidade no ensino de design em instituições federais de ensino superior no Brasil. Mix Sustentável, v. 5, n. 3, p. 109-118, 2017. 
CAPRA, F.; LUISI, P. L. A visão sistêmica da vida: uma concepção unificada e suas implicações filosóficas, políticas, sociais e econômicas. São Paulo: Cultrix, 2014.

CARDOSO, R. Design para um mundo complexo. São Paulo: Cosac Naify, 2013.

CONFORTO, E. C.; AMARAL, D. C.; SILVA, S. L. DA. Roteiro para revisão

bibliográfica sistemática: aplicação no desenvolvimento de produtos e gerenciamento de projetos. In: Congresso Brasileiro de Gestão de

Desenvolvimento de Produto, 8., Porto Alegre, 2011. Disponível em:

http://vision.ime.usp.br/ acmt/conforto.pdf. Acesso em: 15 fev. 2019.

DRESCH, A.; LACERDA, D. P.; ANTUNES JUNIOR, J. A. V. Design Science research: método de pesquisa para avanço da ciência e tecnologia. Porto Alegre: Bookman, 2015.

ENSSLIN, S. R. et al. Avaliar o tratamento do tema sustentabilidade nos Projetos Integradores do Curso Superior de Tecnologia em Design de Produto. Estudos em Design, v. 21, n. 1, p. 1-24, 2013.

EVERLING, M. T.; SOBRAL, J.; CAVALCANTI, A. Design \& o vir a ser: fundamentos de educação e ecologia orientados para um mundo em transformação. Mix Sustentável, v. 6, n. 1, p.135-143, 2020.

GOMES, L. R. Educação através do design e as práticas educacionais sobre consumo sustentável no ensino fundamental público de Curitiba: panorama e possibilidades. $161 \mathrm{f}$. Dissertação (Mestrado em Design) - Universidade Federal do Paraná, Curitiba, 2009.

MANZINI, E.; VEZZOLI, C. O desenvolvimento de produtos sustentáveis: os requisitos ambientais dos produtos industriais. São Paulo: Editora da Universidade de São Paulo, 2002.

MAGALHÃES, R. B. Contribuição da ecologia profunda ao ecodesign: associando estratégias didáticas e tecnológicas no ensino fundamental. $188 \mathrm{f}$. Dissertação (Mestrado em Design) - Universidade Federal do Rio Grande do Sul, Porto Alegre, 2011.

MOL, I. A. Superfícies de um lugar: proposição de método de ensino para design de superfície a partir de valores culturais brasileiros. $122 \mathrm{f}$. Dissertação (Mestrado em Design) - Universidade do Estado de Minas Gerais, Belo Horizonte, 2014.

MORAES, L. M. de. Sistematização de procedimentos do design para a sustentabilidade ambiental para aplicação no ensino de metodologia de projeto. 199 f. Dissertação (Mestrado em Design) - Universidade Federal do Rio Grande do Sul, Porto Alegre, 2011.

MOUCHREK, N. M. Estratégias e competências de design para promover a cultura de sustentabilidade. 149 f. Dissertação (Mestrado em Design) Universidade do Estado de Minas Gerais, Belo Horizonte, 2014. 
MUNIZ, J. P. S.; PAZMINO, A. V. O Design na Educação Ambiental: requisitos para kit interdisciplinar sobre a perda da biodiversidade no Brasil. Mix Sustentável, v. 5, n.2, p. 5570, 2019.

NEVES, L. F. A. Aprendizado baseado em problemas: um novo conceito para a formação do Designer e a Sustentabilidade. 117 f. Dissertação (Mestrado em Design) - Universidade Estadual Paulista, Bauru, 2008.

NEVES, C. A. A. et al. Aplicação de preceitos da educação para sustentabilidade: um estudo de projetos de trabalhos de conclusão no curso superior de tecnologia em design de produto do IFSC. Mix Sustentável, v. 3, p. 81-89, 2016.

NEVES, L. F. A.; ALENCAR, F. de. Aprendizado baseado em problemas, um novo conceito para a formação do designer no viés sustentabilidade. Educação Gráfica, v. edição esp., p. 115-132, 2009.

PAZMINO, A. Jogos de sustentabilidade e eco design: estratégia de ensinagem cinestésica. Mix Sustentável, v. 1, p. 57-68, 2015.

PAZMINO, A. V.; SANTOS, A. S. Design e sustentabilidade: necessidade de quebra de paradigma no ensino. Mix Sustentável, v. 3, n. 1, p. 10-16, 2017.

PINHEIRO, N. Formação em Moda no Caminho da Sustentabilidade. $81 \mathrm{f}$.

Dissertação (Mestrado em Design) - Universidade Estadual Paulista, Bauru, 2012.

SAMPAIO, C. P.; FERROLI, P. C.; SANTOS, A.; CHAVES, L.; ENGLER, R. C.; LEPRE, P. R.; LIBRELOTTO, L.; LOPES, C. S. D; MARTINS, S. B.; NUNES, V. G. A.; TREIN, F. A. Design para a sustentabilidade: dimensão ambiental. Curitiba: Insight, 2018.

SANTOS, A. dos. Níveis de maturidade do design sustentável na dimensão ambiental. In: MORAES, Dijon de; KRUCKEN, Lia (Org.). Design e sustentabilidade. Barbacena: EdUEMG, 2009. p. 13-26.

SANTOS, A. DOS; COSTA, H. Diálogo entre pós-graduação e graduação: a introdução do ensino do design de Sistemas Produto+Serviço na UFPR. Projética, v. 5, n. 1, p. 243255, 2014.

SELAU, L. G. A inserção do tema da sustentabilidade nas disciplinas dos cursos de graduação em design na região metropolitana de Porto Alegre - RS. 155 f. Dissertação (Mestrado em Design) - Centro Universitário Ritter dos Reis, Porto Alegre, 2014.

SILVA, I. F.; CLEMENTINO, T. O.; NEGROMONTE, L. F. Metodologia para inclusão dos princípios de sustentabilidade no ensino de design de produto. Mix sustentável, n. 5, v. 5, p. 81-94, 2019.

SILVA, C. V. DA. Design sustentável: proposta de objeto de aprendizagem para auxílio à elucidação de requisitos de sustentabilidade em projeto de produto. $137 \mathrm{f}$. 
Dissertação (Mestrado em Design) - Centro Universitário Ritter dos Reis, Porto Alegre, 2015.

SILVA, C. V.; RIBEIRO, V. G. A. S. Causa \& Efeito: objeto de aprendizagem para auxílio à elucidação de requisitos de sustentabilidade. Mix Sustentável, v. 2, p. 116125, 2015.

SMYTHE JUNIOR, N. L. Uma proposta de diretrizes para inserção da sustentabilidade em cursos superiores de design gráfico. $145 \mathrm{f}$. Dissertação (Mestrado em Design) - Universidade Federal do Paraná, Curitiba, 2010.

VENÂNCIO, G. A. A valorização de territórios no ensino de design de produto. 162 f. Dissertação (Mestrado em Design) - Universidade Federal do Paraná, Curitiba, 2012.

VEZZOLI, C. Design de sistemas para a sustentabilidade: teoria, métodos e ferramentas para o design sustentável de "sistemas de satisfação". Salvador: EDUFBA, 2010.

VEZZOLI, C. et al. Sistema produto + serviço: fundamentos. Curitiba: Insight, 2018. ZAMBENEDETTI, G. W. O design e a extensão universitária: proposta de diretrizes para análise de projetos extensionistas em comunidades de baixa renda. 118 f. Dissertação (Mestrado em Design) - Centro Universitário Ritter dos Reis, Porto Alegre, 2016. 